\title{
Antecipando o fim: a pandemia que evidenciou as contradições do capitalismo e reacendeu o debate sobre formas de reestruturação e superação
}

Foreseeing the end: the pandemic that highlights the capitalism contradictions and rekindles the debate on restructuring and overcomes

\author{
Elohá Cabreira Brito ${ }^{a}$ \\ Eduardo Maldonado Filho ${ }^{b}$
}

\begin{abstract}
Resumo: A pandemia do COVID-19 evidenciou e aprofundou as contradições do sistema capitalista, levando ao reaparecimento do debate sobre reestruturação do sistema nas discussões políticas e econômicas. Neste contexto, o artigo objetiva evidenciar a insustentabilidade do capitalismo - devido a tais contradições serem inerentes ao sistema - e discutir alternativas para a superação da desigualdade, do desemprego, da exploração e da crise ambiental. Como o modo de produção associado e a Economia de Francisco e Clara. Modelos em que as necessidades do ser humano, seu desenvolvimento e a preservação do meio ambiente são os objetivos centrais do processo produtivo.
\end{abstract}

Palavras-chave: Crises; COVID-19; Modo de Produção Associado; Sustentabilidade Classificação JEL: P19; I10; P40; Q56; A13

\begin{abstract}
The COVID-19 pandemic highlighted and deepened the capitalist system's contradictions, leading to the reappearance of the debate on system restructuring in political and economic discussions. In this context, the article aims to highlight the unsustainability of capitalism - due to such contradictions being inherent to the system -, and discuss options for overcoming inequality, unemployment, exploitation, and environmental crisis. Such as the Associated Mode of Production and the Economy of Francisco and Clara. Models in which the needs of human beings, their development, and environmental preservation are the central objectives of the production process.
\end{abstract}

Keywords: Crises; COVID-19; Associated Mode of Production; Sustainability

JEL Classification: P19; I10; P40; Q56; A13

\footnotetext{
${ }^{\text {a }}$ Bacharela em Ciências Econômicas pela Universidade Estadual de Maringá (UEM). Mestra em Economia Aplicada pela Universidade Estadual de Maringá (2012). Doutoranda em Economia (área de concentração em Economia do Desenvolvimento) pelo PPGE/UFRGS. Email: eloha.cabreira@ gmail.com.

${ }^{\mathrm{b}}$ Professor Aposentado da Faculdade de Ciências Econômicas e do Programa de Pós-Graduação em Economia da Universidade Federal do Rio Grande do Sul (FCE e PPGE/UFRGS). Email: emaldonadof@ gmail.com
} 


\section{Introdução}

No contexto que antecede a pandemia da COVID-19, a economia mundial já exibia sinais de desaquecimento, evidenciando o desgaste do modelo neoliberal e sua incapacidade de gerar crescimento sustentável e sustentado da economia. Além de ressaltar os impactos negativos deste modelo sobre o aprofundamento da pobreza e desigualdade, acompanhado pelo aumento da concentração de renda e riqueza, e para a devastação do meio ambiente. Com a pandemia, esses problemas foram evidenciados e agravados, reacendendo o debate sobre as formas de reestruturação do capitalismo, a partir da interpretação de que os problemas atuais decorrem do modelo neoliberal e não do próprio sistema. Segundo essa visão, a maior intervenção do governo na economia seria necessária para resolver o desemprego, as crises e possibilitar a saída das economias da recessão da pandemia $^{1}$. Contrariamente a esta perspectiva, o objetivo deste artigo é destacar a insustentabilidade do sistema capitalista no longo prazo, bem como apontar as alternativas a essa forma de organização socioeconômica visando superar tais problemas.

A incompatibilidade do sistema capitalista com objetivos além do lucro, como preservação ambiental, saúde pública, e redução da desigualdade contrasta com a falta de alternativas apresentadas pela esquerda, a nível mundial. A situação enfrentada pelo país mais rico do mundo, privilegiado com a possibilidade de emissão da moeda mundialmente aceita, que não conseguiu impedir, ou amenizar, o contágio e o número de mortes de seus cidadãos, e em poucos dias registrou um número de mortes diárias superior à Itália e à Espanha, países notadamente em situação mais preocupante no cenário mundial, notabiliza os limites do mercado, especialmente quando este domina o sistema de saúde ${ }^{2}$.

Cabe ressaltar que nos momentos de crise os economistas e formuladores de política recorrem a teoria de Keynes, à intervenção do Estado na economia para suavizar os ciclos econômicos. Todavia, as profundas contradições inerentes a organização socioeconômica atual, patenteadas e agravadas pela pandemia, não podem ser superadas por esta abordagem. Este artigo visa demostrar que a teoria a ser resgatada neste momento é a de

${ }^{1}$ UNCTAD (2020) apresenta esta visão.

${ }^{2}$ Em março/2020 a Itália e a Espanha ganharam destaques nos noticiários mundiais por apresentar número crescente de mortes diárias. Em 21/03/2020 eram 625 mortes diárias na Itália, atingindo 971 em 28/03/2020, já a Espanha apresentou 877 mortes em 27/03/2020. A rápida propagação da doença, devido a não adoção imediata de medidas de isolamento, levou a sobrecarga do sistema de saúde, forçando os profissionais deste setor a ter que escolher a quem fornecer e a quem negar atendimento adequado. O Brasil registrou 1.595 mortes em 31/07/2020, mas fora a partir de março de 2021 que o número de fatalidades diárias se acelerou de forma significativa, atingindo 4.249 em 10/04/2021. Comportamento semelhante foi observado nos EUA, contudo o pico de fatalidade fora em 17/04/2020, com 6.409 mortes. O total de óbitos pela COVID-19 registrados, nos países supracitados, até 20/05/2021 foram: 79.502 na Espanha, 124.646 na Itália, 439.050 no Brasil, 581.717 nos EUA e 3.412 .032 no mundo (WHO, 2021; SOUZA, 2020). 
Marx ${ }^{3}$, por melhor descrever o sistema capitalista, seus limites e contradições, bem como pela sua concepção de modo de produção associado, que consiste em uma alternativa as relações sociais de produção atual e suas consequências.

Isto posto, o artigo está dividido em cinco seções incluindo esta introdução e as considerações finais. A segunda seção aborda as contradições do capitalismo e sua insustentabilidade no longo prazo. A terceira seção discute o papel da mudança ideológica e da luta de classes na superação destes problemas. Já a quarta seção aborda as alternativas, como o resgate a obra de Marx e sua descrição do modo de produção associado, a proposta de Burkett (2014), de Rigi $(2011,2013)$ e da Economia de Francisco e Clara.

\section{Contradições e sustentabilidade do capitalismo no longo prazo}

As contradições inerentes ao sistema capitalista foram destacadas por Marx, especialmente, em sua obra "O Capital". Atualmente essas contradições têm se intensificado com o modelo neoliberal a ponto de pesquisadores do próprio FMI, Ostry, Loungani e Furceri (2016), reconhecerem os custos evidentes das políticas neoliberais sobre as economias, particularmente as emergentes, em razão de seus efeitos deletérios sobre a pobreza e desigualdade, e o impacto negativo sobre o crescimento econômico e sua sustentabilidade ${ }^{4}$.

A pandemia da COVID-19 só acentuou os problemas que as economias capitalistas já enfrentavam, o desaquecimento das economias, aumento da pobreza, desigualdade e informalidade. No Brasil, a redução dos direitos trabalhistas e a reforma previdenciária recaíram com maior peso sobre os mais pobres não reverteram e, sim intensificaram, a desigualdade e pobreza ${ }^{5}$. Mesmo as economias de capitalismo avançado não estão imunes as contradições deste sistema ${ }^{6}$. Neste contexto é importante discutir os problemas inerentes ao sistema capitalista visando analisar sua sustentabilidade no longo prazo, objeto de estudo das próximas subseções.

\footnotetext{
${ }^{3}$ Embora existam diferentes interpretações quanto aos limites do capitalismo, como expõe Roberts (2020a).

${ }^{4}$ Cabe destacar que tais pesquisadores, diferindo da interpretação de Marx, não reconhecem os problemas intrínsecos ao capitalismo, somente ao modelo neoliberal.

${ }^{5}$ Segundo IBGE (2019) em 2018 houve aumento do rendimento dos $10 \%$ mais ricos e redução do rendimento dos $40 \%$ mais pobres, acarretando um rendimento 13 vezes maior do primeiro grupo em relação ao segundo. Essa diferença no aumento dos rendimentos, a redução do emprego formal e o aumento da subutilização da força de trabalho são apontados como relevantes para o crescimento da desigualdade e da extrema pobreza ocorridos no período.
}

${ }^{6}$ Assunto abordado por Maldonado Filho (2013) e Roberts (2020). 


\subsection{A lucratividade e o crescimento econômico}

A única finalidade da produção capitalista é a obtenção contínua de lucros, valorização do capital, concretizada por meio da ampliação contínua dos investimentos cujo motor é taxa de lucro. Portanto, a redução desta paralisa esse movimento do capital, retardando a formação de novos capitais, resultando em um excesso de capital em relação as oportunidades de investimentos lucrativos, levando à crise (MARX, 2008).

A função da crise é destruir os capitais excedentes (físicos e fictícios) que impedem a elevação da taxa de lucro, restaurando assim, ainda que temporariamente, as condições de acumulação de capital. Essa é uma das contradições do capitalismo apontada por Marx, sendo o modo de produção que mais produz riqueza, necessita periodicamente destruir o excesso de riqueza produzida, para manter as condições de lucratividade, motor da acumulação capitalista. Assim, a crise, a destruição de riqueza, não é só inerente, mas necessária ao sistema capitalista. "A taxa de lucro é a força propulsora da produção capitalista, e só se produz o que se pode e quando se pode produzir com lucro" (MARX, 2008, p. 338).

A redução da lucratividade do capital e suas implicações para o crescimento das economias nas últimas décadas, decorrente da lei geral da queda tendencial da taxa de lucro, foi abordada por diversos autores, como Maldonado Filho (2013) e Roberts (2020).

Maldonado Filho (2013) discute a queda do dinamismo da economia norteamericana, e mundial, desde os anos 1980, alicerçado na teoria de Marx sobre as crises capitalistas. Segundo o autor, esse declínio no dinamismo evidencia o excesso de capital em relação as oportunidades de investimento lucrativo e a necessidade de crise para restaurar as condições de lucratividade. Se o governo impedir a queima de capital, promovida pela crise, o sistema não reestabelecerá as condições de elevada rentabilidade que impulsionam o dinamismo da acumulação.

Deste modo, as políticas governamentais que visam suavizar os efeitos da crise implicam o baixo crescimento ou estagnação. Embora importantes para reduzir o impacto da crise sobre os indivíduos, especialmente os mais vulneráveis a ela, como os trabalhadores, tais políticas têm o custo de impedir a queima de capital em montante necessário ao reestabelecimento das condições de rentabilidade, essenciais para a retomada do dinamismo da acumulação capitalista.

Roberts (2020) corrobora com essa visão ao enfatizar o problema da baixa rentabilidade do capital, como a causa da longa depressão dos investimentos, que ocorreu nas primeiras décadas do século XXI, período no qual a lucratividade do capital mantevese próxima das mínimas históricas. Após evidenciar a incapacidade da teoria mainstream em explicar as crises capitalistas, o autor apresenta a teoria de Marx sobre a lei da queda da taxa de lucro, os fatores contrários à lei $^{7} \mathrm{e}$ aponta fortes evidências empíricas existentes, tanto em trabalhos de autores marxistas quanto do mainstream, sobre o comportamento

\footnotetext{
${ }^{7}$ De acordo com Marx (2008) são esses fatores que tornam a lei geral da queda da taxa de lucro em tendencia Tais fatores podem mitigar, ou reverter, a queda da taxa de lucro, mas apresentam seus próprios limites e não invalidam a lei geral. Como sublinhado por Roberts (2020a), esta apresenta um caráter cíclico e secular.
} 
declinante da taxa de lucro do capital no longo prazo de diversas economias e da média global, bem como sobre os períodos em que os fatores contrários inverteram, temporariamente, a tendência a queda.

De acordo com Roberts (2020), a estagnação do crescimento da década de 2010 é explicada pelo baixo investimento no setor produtivo devido a reduzida lucratividade, que acarretou baixo crescimento real do PIB e da produtividade; e pela guerra comercial entre EUA e China, que reduziu investimento tecnológico. Já os fatores que adiaram a recessão iminente, devido à baixa lucratividade do capital, foram: i) a transferência de valor das economias dominadas (da América Latina) às nações imperialistas; ii) o crescimento da dívida corporativa e soberana (capital fictício); e iii) a ampliação do emprego de mão de obra com baixos salários e precarizada (sem direitos trabalhistas) (ROBERTS, 2020).

Embora tais fatores contribuíram para o adiamento da recessão, não são suficientes para impedir a ocorrência desta. Cabe destacar que a lucratividade consiste no indicador mais importante das economias capitalistas, pois determina a continuidade do investimento e da produção. A reduzida lucratividade evidencia a proximidade de uma recessão, necessária para um novo período de expansão da acumulação (ROBERTS, 2020).

O autor aponta, e concordamos com essa visão, que mesmo a retomada da acumulação não eliminará os desafios contemporâneos, que ameaçam o capitalismo, a saber: i) a mudança climática e o aquecimento global; ii) a elevada desigualdade e as tensões sociais resultantes; iii) o aumento da rivalidade entre as nações capitalistas, como EUA e China; iv) a possibilidade de novas guerras devido à tendência a queda da lucratividade ampliar a concorrência entre os capitais no mercado mundial; v) o crescimento do proletariado; vi) a incapacidade do capital atender as necessidades humanas.

Assim, além das constantes crises de rentabilidade do capitalismo, tal sistema apresenta outras consequências negativas que tem se aprofundado na atualidade e patenteiam a insustentabilidade do capitalismo, a mais grave destas é o colapso ambiental e social.

\subsection{A devastação ambiental e humana}

O descaso do capital pela natureza e pela vida humana foram destacados por diversos autores, como Klein (2014), Bello (2009) e Wengraf (2018), além de Marx. Enquanto Klein (2014) analisa os problemas ambientais e seus nocivos impactos, que começam a aparecer, mas que se intensificarão nos próximos anos. Bello (2009) aborda a crise alimentar, que se agravou com a elevação dos preços das commodities entre 2006 e 2008, acarretando ampliação da fome em mais de 36 economias, ao encarecer alimentos básicos tornando-os inacessíveis a elevada parcela da população mundial. Já Wengraf (2018), centra-se nos problemas do colonialismo passado e contemporâneo sobre as nações africanas, contestando a existência de uma maldição de recursos naturais em tais economias.

Klein (2014) ressalta que devido à gravidade da crise climática, em virtude do seu potencial para extinguir não só a espécie humana, como muitas outras, é preciso mudar 
tudo, do estilo de vida à forma de funcionamento da economia. Contudo, diferentemente das ações e mobilização de recursos para mitigar uma crise bancária, que só ameaçaria o sistema econômico, os governos não têm adotado nenhuma medida efetiva para reverter os problemas climáticos que segundo previsões, atualmente consideradas otimistas ${ }^{8}$, elevará a temperatura do planeta em 2 graus célsius.

As consequências desse aquecimento seriam ondas de calor extremo, desertificação de algumas regiões, elevação do nível do mar a ponto de submergir diversas cidades costeiras, afetaria gravemente a produção de alimentos, diversos ecossistemas e a biodiversidade. Em razão do calor, das pestes, de alagamentos, e outros desastres climáticos que serão mais frequentes, milhares de pessoas precisariam migrar para regiões habitáveis. Presumindo que seria possível a adaptação humana a essa nova realidade, o que ainda não é certo. Além disso, parece improvável uma organização social pacífica neste cenário, considerando a estabilização da elevação da temperatura mundial média em cerca de 4 graus célsius, sem contínuo aumento desta, o que previsões mais atualizadas contestam (KLEIN, 2014).

Embora as consequências mais drásticas do aquecimento global são esperados até $2100^{9}$, outras já aparecerão nos próximos anos. Conforme aponta um estudo de abril de 2020, da McKinsey Global Institute, que apresenta os riscos da mudança climática e seus impactos socioeconômicos no mercado imobiliário e hipotecário na Flórida, com projeções para as próximas três décadas ${ }^{10}$. Estimando uma queda de 30 a 80 bilhões de dólares no valor de mercado dos imóveis até 2050. Apesar de sofrer constantes alagamentos, furacões e tempestades tropicais, o clima agradável e as belas praias transformaram esse estado em uma atrativa opção de investimento imobiliário. Todavia o risco de tal investimento cresceu em consequência das mudanças climática, pois, além de consistir em um território de baixa altitude e ampla área costeira, os múltiplos riscos climáticos a que está submetido, tendem a se intensificar e aumentar sua frequência em virtude do aquecimento global (WOETZEL et al., 2020). Além das perdas materiais, esse cenário também traz perdas humanas, mas ainda está sendo ignorado.

O consenso científico sobre a crise climática não mobilizou os governos em razão das ações necessárias para melhorar os prognósticos da crise ambiental $^{11}$ não serem compatíveis com o sistema capitalista desregulamentado da atualidade. Nem com a estrutura de poder de uma minoria que domina a sociedade atual através da economia, da política e da mídia. Os primeiros estudos sobre mudanças climáticas surgiram no período em que se propagavam a ideologia neoliberal, dificultando a adoção de medidas como o aumento de impostos sobre atividades poluentes. A própria desregulamentação de grandes

${ }^{8} \mathrm{O}$ cenário mais realista, já abordado pelo próprio Banco Mundial, aponta para 4 graus célsius até 2100.

${ }^{9}$ Conforme Klein (2014), mas a cada ano as previsões científicas antecipam essa data.

${ }^{10}$ Tempo de quitação de um financiamento realizado na data do estudo.

${ }^{11}$ É importante destacar que tais medidas poderiam beneficiar grande parte da população mundial, por também solucionar outras consequências negativas do capitalismo como a desigualdade, desemprego e pobreza. 
multinacionais, deste período, contribuiu para o aumento da emissão de gases de efeito estufa (KLEIN, 2014).

A lógica capitalista da contínua busca de lucros crescentes, possibilitada somente pela contínua expansão da acumulação não é compatível com a redução do uso de recursos naturais, da produção que gera emissão de gases de efeito estufa, do uso de combustíveis fósseis. Essa conclusão não é apontada somente por Klein (2014), mas por diversos autores, como Burkett (2014), Bello (2009), Wengraf (2018). Entretanto, aparece pioneiramente nas obras de Marx, segundo o qual a produção capitalista "só desenvolve a técnica e a combinação do processo social de produção, exaurindo as fontes originais de riqueza: a terra e o trabalho" (MARX, 2016, p. 571). O autor também destaca a incapacidade de medidas que contrabalanceiem a destruição ambiental de acompanhar o ritmo imposto pela acumulação capitalista: "O desenvolvimento da cultura agrícola e da indústria se tem revelado tão eficaz na destruição das florestas que o que se tem feito no sentido de conservá-las e regenerá-las não passa de uma grandeza que se desvanece inteiramente" (MARX, 2016a, p. 277). A pandemia COVID-19 é consequência dessa degradação ambiental, e a continuidade de tal comportamento implica surgimento de novas pandemias no futuro ${ }^{12}$.

Abordando outra consequência nefasta do sistema capitalista, as guerras alimentares e a fome, Bello (2009) se afasta da visão ortodoxa destacando que a própria expansão do consumo chinês e indiano, não foi tão importante para as crises alimentares quanto: i) a mudança no padrão de consumo chinês que ampliou a demanda por carnes, levando a um aumento de plantações de soja destinada à alimentação animal; ii) o deslocamento da especulação imobiliária, após crise 2007/2008, para as commodities no mercado futuro; iii) uso de alimentos em biocombustíveis etc. (BELLO, 2009).

Contudo, as políticas de ajuste estrutural que o Banco Mundial e o FMI impuseram, desde os anos 1980, aos países periféricos, que retirou o apoio governamental da agricultura, especialmente na África, tiveram papel central na crise alimentar de tais países, ao transformá-los de exportadores líquidos de alimentos em grandes importadores destes. Em 2008 o Banco Mundial reconheceu que os resultados esperados por tais políticas não foram alcançados (BELLO, 2009). Em 2010, Bill Clinton, ex-presidente dos EUA, admitiu que suas políticas comerciais impostas ao Haiti destruíram a capacidade de tal país ser autossuficiente na produção deste grão, se desculpando publicamente (BILL..., 2016). Esses reconhecimentos não eliminaram a fome enfrentada por tais populações, em razão dos empecilhos ao desenvolvimento de sua capacidade produtiva agrícola, impostos pela política neoliberal que foram forçadas a seguir. Nem foram acompanhadas de reparações, como ocorre quando há reconhecimento de políticas equivocadas aplicadas ao capital.

Os defensores da agricultura camponesa apontam que a exploração capitalista da agricultura (agronegócio) é responsável pela crise de segurança alimentar e pelos problemas ecológicos e sociais. Uma vez que a alocação do capital entre os setores e/ou atividades (produção de alimentos, combustível ou ração animal) é realizado somente com

${ }^{12}$ Mais detalhes em Layrargues (2020). 
base na lucratividade, sendo a "satisfação das necessidades reais da maior parte da população uma preocupação secundária, se é que de fato entra no cálculo" (BELLO, 2009, p. 16, tradução nossa). Neste contexto, o autor ressalta que, o "modo camponês" adquire relevância para todos os afetados negativamente pelo capitalismo.

Wengraf (2018), também retrata os impactos do capitalismo no meio ambiente e nas condições de vida e trabalho dos trabalhadores no contexto da nova corrida à África liderada pelos EUA e China. Tal análise revela que as raízes da devastação ambiental, elevada pobreza, desemprego e guerras, não decorrem de uma maldição devido à abundância de recursos naturais, mas do colonialismo que predominou no passado, e no imperialismo e neoliberalismo que ainda são impostos a esse continente pelas nações desenvolvidas. É a extração de lucro como finalidade das nações desenvolvidas que amaldiçoou e continua amaldiçoando o continente africano. As exigências de programas de ajustes estrutural, tais como o pagamento de débitos a qualquer custo, inclusive através de cortes de programas sociais (educação, saúde, segurança etc.), impostas pelo FMI, foram danosos a economia e à população.

Segundo Wengraf (2018), essas políticas neoliberais não acarretaram crescimento econômico, mas contribuíram, diretamente, para o aumento: i) da parcela da população em situação de pobreza; ii) da insegurança alimentar; iii) da taxa de desemprego; iv) da desindustrialização; v) da devastação ambiental; vi) da instabilidade e fragilidade das economias; e vii) de guerras. Contribuíram para a devastação da agricultura e da indústria africana, não gerando desenvolvimento tecnológico ou industrial. Tais evidências obrigaram os antigos defensores do neoliberalismo, a autora cita Stiglitz, a reconhecer a inadequação de tal modelo para o desenvolvimento econômico.

Além dos problemas das políticas neoliberais, o continente africano enfrenta outra ameaça: as potenciais consequências negativas da rivalidade entre China e EUA, cuja presença se amplia no território africano, com o aumento dos níveis de militarização em diversos países conduzidos pelos EUA (WENGRAF, 2018).

O pano de fundo comum a análise de Klein (2014), Bello (2009) e Wengraf (2018) é a necessidade de valorização do capital a qualquer custo, sem nenhuma consideração com as consequências negativas sobre o meio ambiente e o ser humano. Se os investimentos forem lucrativos, se aceita a devastação ambiental, a fome, a exploração de nações não desenvolvidas, entre outros. A partir da abordagem de Marx (2008), compreende-se que estes são fatores contrários à lei da queda tendencial da taxa de lucro.

\subsection{A exploração da força de trabalho}

Outro fator contrário à lei geral, é a exploração da força de trabalho. Fuchs (2014) aborda este tema na atualidade ao descrever as condições de trabalho nas cadeias globais de valor do setor de tecnologia da informação e comunicação que, em razão da nova divisão 
internacional do trabalho, se distribui por muitas nações ${ }^{13}$. O autor destaca as precárias condições de trabalho marcadas pela extrema exploração dos trabalhadores e apropriação de dados de usuários sem compensação para garantir elevados lucros as grandes companhias de dispositivos e mídias digitais, como: Apple, Acer, Dell, Lenovo, Samsung, Facebook, Youtube.

$\mathrm{O}$ autor ressalta que as condições de trabalho na extração de minério ${ }^{14} \mathrm{em}$ algumas nações africanas são análogas à escravidão. Nestas há trabalho infantil, contratos de trabalhos precários e mal remunerados, deslocamento de comunidades, degradação da terra, poluição do meio ambiente, do ar, dos rios e da água usada pela população. O que causa doenças respiratórias, pulmonares, lesões na pele, ossos e articulações dos trabalhadores, entre outras enfermidades decorrente da precariedade do ambiente em que trabalham e vivem, sem acesso as condições sanitárias mais básicas, e da fome causada pelos baixos salários. O trabalho nas minas é predominantemente artesanal e em condições de escravidão moderna, as greves são encerradas através da intervenção policial que resultam em morte e ferimento de muitos trabalhadores, entre outros problemas. Os trabalhadores se submetem a este tipo de ocupação pelo contexto de violência e fome de seus países, que os levam a aceitarem qualquer tipo de coisa pela sua sobrevivência (FUCHS, 2014).

Tais condições de vida e trabalho são semelhantes as descritas por Marx (2016, $2015)^{15}$ a respeito dos trabalhadores fabris ingleses de sua época, mas agravada pela violência e escravização da mão de obra de adultos e crianças. Estas condições também se assemelham a dos trabalhadores do setor de montagem dos iPad, iPod, iPhone, ou Apple Macintosh, na China, cujas condições de trabalho levam a muitos recorrem ao suicídio (FUCHS, 2014).

O autor ainda aborda a exploração da mão de obra altamente qualificada indiana na produção de software. Que aufere menores salários, em média entre $7 \%$ e $40 \%$ da remuneração devida a trabalhadores dos EUA, sem compromissos trabalhistas e garantias de segurança de emprego, bem como a imposição de longas jornadas sem pagamento de horas extras, estabelecimento de prazo curtos que aumentam a pressão sobre os trabalhadores e sujeito a constantes deslocamentos ao arbítrio do capital (FUCHS, 2014).

Outros casos de condições de trabalho degradantes se manifesta no lado oculto de Silicon Valley, nos EUA, que esconde a exploração, o racismo, a toxicidade dos ambientes de trabalho e habitação dos trabalhadores ${ }^{16}$. Essas condições resultaram em mortes, abortos

\footnotetext{
${ }^{13}$ EUA (desenvolvimento de software, mídias digitais e centrais de atendimento), Índia (desenvolvimento de software), China (montagem) e nações africanas (extração de minério).

14 Matéria-prima essencial para a produção de dispositivos eletrônicos (como: tablets, notebooks e smartphones).

${ }^{15}$ Cuja publicação original é de 1867.

${ }^{16} \mathrm{O}$ autor ressalta que os metais pesados contaminam, além do ambiente de trabalho, a água, ar e solo, das regiões de residência dos imigrantes, que estão duplamente expostos a contaminação, em sua moradia e em seu trabalho.
} 
espontâneos, esterilidade, leite materno tóxico, malformações em recém-nascidos, doenças cardíacas, neurológicas, respiratórias e diversos tipos de câncer nos trabalhadores e seus descendentes. Bem como a sobrecarga de trabalho e o estresse a que estes são submetidos (FUCHS, 2014).

Assim, a partir do apresentado por Fuchs (2014) é evidente o descaso com a saúde dos trabalhadores, com suas condições de vida e trabalho, bem como o descaso com o meio ambiente que a lógica de acumulação que busca incessantemente lucros crescentes do sistema capitalista possui, e seus graves impactos sobre grande parcela dos seres humanos e sobre a natureza.

Tais impactos estão sendo aprofundados na atualidade pela pandemia e pela quarta revolução industrial ${ }^{17}$. As evidências indicam a possível intensificação da tendência a automação do processo produtivo no pós-pandemia, uma vez que em razão das medidas de isolamento social impostas pelo poder público para mitigar a propagação da doença, houve um crescimento da adoção de tecnologias digitais, home office, lojas virtuais, entre outros. Contudo, estas mudanças inicialmente implantadas em caráter temporário, mostraram a maior lucratividade e produtividade, bem como a possibilidade de redução de custos, como os de infraestrutura e deslocamento (MENDES; HASTENREITER FILHO; TELLECHEA, 2020; HAUBRICH; FROEHLICH, 2020). A maior digitalização da economia no período da pandemia, evidenciada pelo aumento das vendas e prestação de serviços por meio de plataformas digitais, pode assumir um caráter duradouro no pós-pandemia, ameaçando diversas vagas de emprego, por exemplo, as do setor de varejo.

Assim, essa tendência a automação, impulsionada pelo desenvolvimento tecnológico, pela lógica capitalista ${ }^{18}$ e pela pandemia contribuiria para o aumento da precarização do trabalho, decorrente do crescimento do desemprego e de pressões para tornar o trabalho humano competitivo em relação ao uso das máquinas. Expondo mais uma razão da insustentabilidade ${ }^{19}$ do capitalismo e a necessidade de se discutir alternativas concretas, tema das próximas seções.

\footnotetext{
${ }^{17}$ Para mais detalhes ver: Autor (2015); Degryse (2016); Frey e Osborne (2017); Ford (2015); Schwab (2016); UNCTAD (2020).

${ }^{18}$ Marx (2016) salienta que a tendência a automação se deve, além da busca por aumento da produtividade e competitividade, a contínua luta do capital com o trabalhador sobre o controle do processo produtivo. Para acabar com a constante insubordinação dos trabalhadores, com a falta de disciplina destes.

${ }^{19}$ Além dessas crises, há a crise do sistema capitalista na esfera política. Sobre o tema ver: Andrade (2019).
} 


\section{A luta de classes e a mudança ideológica}

A superação do sistema que acarreta tantos problemas sociais e ambientais, demanda uma mudança ideológica dos indivíduos, uma verdadeira revolução ideológica, semelhante a introduzida pela burguesia no contexto da revolução industrial ${ }^{20}$ o que não ocorre de forma rápida e homogênea. A luta de classes, que assume a forma de uma pressão da classe trabalhadora contra a defesa do status quo da classe capitalista, é essencial para a mudança de organização do modo de produção social, uma vez que, como apontou Maldonado Filho (2005), mesmo a mudança de organização da produção no sistema capitalista do liberalismo econômico, que entrou em colapso no pós-guerra com a Grande Depressão, para o capitalismo regulado, não foi implementada sem a oposição dos capitalistas, só sendo possibilitada pela mobilização dos trabalhadores e pressão popular num contexto de uma crise severa e prolongada.

Além de destacar a impossibilidade da emancipação da classe trabalhadora no sistema capitalista, uma vez que este implica o domínio do capital sob o trabalho, Marx $(2012,2011)^{21}$ ressalta que a revolução não pode ser realizada na ausência de condições materiais adequadas (crises). As revoluções só ocorrem quando as condições materiais impelem o proletariado a lutar contra a classe que o oprime. Neste mesmo sentido Burkett (2014, n.p., tradução nossa) aponta que "as lutas da classe trabalhadora por melhores condições de vida e trabalho adquirem um significado adicional nos períodos de crise e reestruturação do capital, quando a contradição entre a lucratividade privada e as necessidades sociais e humanas é mais intensa". O aumento destas contradições decorre da superação das crises se processar através da destruição do capital excessivo às condições normais de lucratividade, via redução dos salários, intensificação do trabalho, depreciação etc.

Na disputa entre capitalismo desregulamentado e meio ambiente, Klein (2014) aponta que até o momento é o modelo econômico tem ganhado a guerra, para reverter essa posição, a autora também destaca a essencialidade de uma mudança ideológica, cultural, uma nova visão de mundo e uma alteração na estrutura de poder, para que o bem comum e a sustentabilidade, predomine sobre a busca de lucro. Somente "movimentos sociais de massa" podem mudar esse cenário. Todavia, para a autora, o maior problema é a ideologia do individualismo, que impede a ação coletiva massiva em direção a uma sociedade melhor. Neste contexto, a superação da teoria econômica convencional, amplamente difundida nos livros textos, é um importante passo. Além de ultrapassada, a teoria mainstream não explica a realidade (ROBERTS, 2020) ${ }^{22}$. Sua manutenção e destaque nos

\footnotetext{
${ }^{20}$ De acordo com Przeworki (1989) a sociedade burguesa se tornou a encarnação do universalismo. O autor cita Gramsci (1971) ao enfatizar que pela primeira vez na história a classe economicamente dominante, se apresentou como o futuro de toda a sociedade. Destacando a igualdade entre indivíduos e a harmonia de interesses.

${ }^{21}$ Obras originalmente publicadas em 1850 e 1852, respectivamente.

${ }^{22} \mathrm{O}$ autor aponta que o mainstream não conseguiu explicar, mesmo após o fato, as causas da crise do subprime, a Grande Recessão ou Longa Depressão e, consequentemente, não consegue apontar medidas para a
} 
livros textos de economia e nas ciências econômicas, juntamente ao mito autorizado do livre mercado, só se justificam, como apontado por Dugger (1988), por se tratar de uma ideologia que fundamenta o status quo ${ }^{23}$.

Assim como a crise ambiental, a pandemia do coronavírus, gera a oportunidade, ou condições materiais para a revolução do sistema, em direção, não somente a uma sociedade que preserve o meio ambiente, mas que se reestruture para eliminar a pobreza, a fome, e outros males. Embora nem todas as economias possuam as condições materiais para o novo, se liderado pelas nações de capitalismo avançado e forjada uma cooperação internacional a mudança se torna factível. Todavia, sem um amplo movimento que demande a mudança, o capital encontrará formas de valorizar-se, se apoiando nos fatores contrários à lei geral da queda tendencial da taxa de lucro, e suas consequências nocivas, abordadas na seção anterior, se intensificarão.

Como já apontado, os problemas ambientais e sociais, que tem se agravado a cada dia, são inerentes a lógica capitalista. Eles evidenciam a urgência da mudança em direção a uma sociedade que priorize o ser humano e a preservação do meio ambiente. Tal mudança deve vir da base, da organização de todos os extratos sociais que são afetados pela lógica capitalista e não integram a pequena minoria que se apropria dos lucros obtidos pela exploração das condições sociais e naturais. Deve-se iniciar com uma revolução culturalideológica centrada no ser humano e no coletivismo.

Embora desafiador, Klein (2014), Bello (2009) e Wengraf (2018) mostram a existência de movimentos de resistência que continuam lutando por uma sociedade baseada em tais princípios. Cabe ressaltar que uma mudança significativa tem como requisito o rápido crescimento destes movimentos, Marx (1970) estava certo ao salientar que o único poder social dos trabalhadores está em seu número. $\mathrm{O}$ contexto atual pode marcar um ponto de inflexão para essa revolução ideológica.

Nenhum modelo anterior a 2020, previa que o isolamento social necessário para deter a curva de contágio, paralisaria diversos setores produtivos. Nem seu impacto positivo na redução de emissões de gases do efeito estufa e na desaceleração da rotina social levariam, por exemplo: a água dos canais de Veneza a se tornar cristalina; a melhoria significativa da qualidade do ar em diversos países, com redução no nível de dióxido de nitrogênio e dióxido de carbono na atmosfera; além do aparecimento de diversos animais silvestres em áreas urbanas "desertas" e com menores índices de poluição ${ }^{24}$.

Esses efeitos embora temporários, são fenômenos empíricos incontestáveis de que a sociedade conduzida pela lógica capitalista que é responsável pela devastação do meio ambiente e que a alteração dela pode significar um destino diferente das catastróficas previsões científicas. Além disso, o enfoque na solidariedade e empatia necessários a esse

retomada do crescimento. Para enfatizar essa incapacidade Roberts (2020) cita Alan Greenspan, Eugene Fama, Gregory Mankiw, entre outros.

${ }^{23}$ Outros trabalhos que também ressaltam o papel ideológico da teoria econômica mainstream em defesa do capitalismo são Fine (2002 e 2017).

${ }^{24}$ Pandemia...(2020). 
momento, a defesa da primazia da saúde coletiva ante a economia, pode ser o início de uma mudança ideológica mais voltada à união e não ao individualismo.

Contudo, mesmo em conjuntura tão adversa, com elevado número de mortes, no Brasil e no mundo, de baixa capacidade ociosa em hospitais, em que se amplia a importância da união para a superação desta pandemia, o individualismo se manifesta em atitudes de descaso com a saúde e vida alheia, em pessoas que se recusam a cumprir os protocolos de saúde pública, como o uso de máscaras, evitar aglomerações, se manter em isolamento social, no negacionismo científico, entre outros. Esta realidade evidencia como uma mudança cultural não se processa rapidamente, mesmo diante de uma pandemia com efeitos negativos sem precedentes sobre a saúde pública e sobre a economia.

\section{As alternativas: o ser humano no centro do sistema socioeconômico (ou o verdadeiro humanismo)}

As consequências negativas do capitalismo que afeta grande parcela da população na atualidade, e toda a humanidade no futuro, implicam necessidade de superação desta forma de organização social. Mas, qual direção seguir?

Algumas propostas surgem relacionadas ao modo de produção associado descrito por Marx e Engels em diversas obras ${ }^{25}$. Como Burkett (2014) e Rigi (2011, 2013) (analisadas na subseção 4.1), bem como a Economia de Francisco e Clara, liderada pelo Papa Francisco (analisada na seção 4.2) ${ }^{26}$.

\subsection{O modo de produção associado: tecnologia e sustentabilidade}

Para Marx não há distinção entre socialismo, comunismo ou modo de produção associado. Além disso, o socialismo apresentado pelo autor, difere significativamente do real, e do conceituado pelo marxismo-leninismo ${ }^{27}$. Os traços essenciais do modo de

${ }^{25}$ Como aponta Maldonado Filho (2005, p. 23), essa proposta de Marx caracteriza-se por ser intrinsecamente democrática, "a organização e regulação econômica, social e política da sociedade" se processa, no modo de produção associado, por vias democráticas, diferindo do capitalismo, em que os mercados assumem tal função.

${ }^{26}$ Além destas, tem-se propostas marxistas de um socialismo de mercado, como em Jossa (2012), de um sistema de cooperativas de mercado, bem como as de David Schweickart e de Michael Howard, abordadas por Chattopadhyay (2018). É nosso entendimento que os modelos de socialismo de mercado, não constituem alternativas reais ao capitalismo, mas formas de reestruturação deste. Para uma análise crítica desta visão à luz do pensamento de Marx ver Chattopadhyay (2018).

${ }^{27} \mathrm{O}$ socialismo real, que entrou em colapso nos países do Leste Europeu, especialmente, na União Soviética, simbolizado pela queda do muro de Berlim, não foi o idealizado por Marx que objetivava o fim da alienação dos indivíduos e a sua plena realização. E sim baseado na concepção menos abrangente, de Lenin, que se pauta nas relações de propriedade e não, como Marx preconizava, nas relações sociais de produção (MALDONADO FILHO, 2005). 
produção associado, segundo Marx (2012a), são: i) a abolição das diferenças de classes, que acarretaria o desaparecimento da desigualdade social e política; ii) a importância da natureza na produção de valores de uso; iii) a noção de que a diversidade individual deve ser considerada na noção de justiça, bem como que cada membro da sociedade deve contribuir de acordo com sua capacidade e receber de acordo com suas necessidades; iv) a essencialidade de algumas deduções da produção social para a reprodução (e sua ampliação), fundo de contingência (como desastres naturais que afetam a produção etc.), despesas de administração, o atendimento das necessidades comuns da sociedade (sistema de educação e saúde) e fundo para trabalhadores incapacitados; v) a oposição de um papel do "atual ordenamento estatal" na construção do comunismo, pois o único papel do Estado será na transição entre o capitalismo e comunismo com a ditadura do proletariado ${ }^{28}$, esta transformação da sociedade deve proceder por vias revolucionárias e deve subordinar o Estado à sociedade, e não o oposto; vi) a importância da internacionalização do movimento operário, uma vez que a burguesia mundial se une para destruir o movimento proletário; vii) a importância do ensino técnico, teórico e prático, que deveria compor as demandas da classe operária; viii) a definição clara das condições aceitáveis ao trabalho feminino e infantil, sendo que este último, seria aceitável, desde que devidamente regulamentado, protegido e acompanhado de educação.

Embora Marx não aborde diretamente os problemas ambientais não os negligencia, pois sua análise enfatiza como os elementos sociais e materiais do processo produtivo são moldados e limitados pelas condições naturais. Burkett (2014, n.p., tradução nossa) aponta que o modo de produção associativo, de Marx e Engels, seria compatível com um modo de produção ecologicamente sustentável.

O princípio básico do modo de produção associado é a restauração da união entre os produtores e as condições de produção, em uma nova forma histórica, com "desmercadorização" ou "desmercantilização" da força de trabalho e "um novo conjunto de direitos de propriedade comunal". A produção social deve ser administrada, planejada e executada coletivamente pelos próprios produtores visando os objetivos estabelecidos de forma democrática e cooperativa, e portanto, garantindo aos membros desta sociedade a satisfação das suas necessidades existenciais e o desenvolvimento de suas capacidades. Marx entendia que este sistema levaria ao livre desenvolvimento humano e a emancipação do trabalhador, pois, enquanto no sistema capitalista há a subordinação real do trabalho ao capital, no comunismo, "são os trabalhadores, como sujeitos, que empregam os meios de produção ... a fim de produzir riqueza para si mesmo" (MARX, 1968 apud BURKETT, 2014, n.p.).

\footnotetext{
${ }^{28}$ Que não deve ser confundida com um modelo ditatorial contemporâneo, uma vez que Marx se baseia nas ditaduras romanas, instauradas nos momentos de crises, como na guerra, para garantir a defesa do território e manutenção do ordenamento constitucional. A ditadura do proletariado, de todo o proletariado e não somente de um grupo, teria o mesmo caráter temporário, mas objetivaria a construção e consolidação do novo sistema, semelhante a Comuna de Paris. Uma excelente referência sobre o tema é Hunt (1974).
} 
Segundo Marx (2016), a partir da propriedade comunal dos meios de produção toda a produção se torna social, sendo uma parte destinada à reprodução (acumulação) e outra ao consumo dos membros da sociedade. A distribuição desta dependerá da forma de organização comunitária e do grau de evolução social, ou seja, da superação das instituições herdadas do capitalismo ${ }^{29}$. A ideia implícita na questão a distribuição é que como as pessoas são diferentes, não devem contribuir e receber na mesma proporção. Marx não defende uma sociedade igualitária e homogênea, em razão da diversidade e liberdade esta será heterogênea, embora exista a igualdade de oportunidades.

Com todos se tornando produtores, as classes sociais deixariam de existir. A divisão entre ciência natural e social desaparece. Com a administração e produção coletiva, as trocas de mercadorias e a moeda também. Assim como a alienação, uma vez que na vida comunitária seus integrantes participam conscientemente do planejamento e execução das ações necessárias para atingir os objetivos coletiva e democraticamente estabelecidos. Neste modelo o poder do Estado foi absorvido pela sociedade (BURKETT, 2014). Nota-se a grande diferença entre o modo de produção associado, descrito por Marx e Engels, do marxismo-leninismo e das experiências do socialismo real.

Além disso, Marx defende que somente nesta sociedade todos os indivíduos conseguem alcançar a verdadeira liberdade, no sentido do desenvolvimento humano com um fim em si mesmo, além da esfera da produção e das necessidades humanas. Uma vez que possibilita a redução do tempo de trabalho, e aumento do tempo livre considerado a verdadeira medida de riqueza (BURKETT, 2014). Somente neste modo de produção o verdadeiro humanismo seria possível com o atendimento das necessidades ${ }^{30}$ e o próprio autodesenvolvimento humano como motor da produção.

De acordo com Burkett (2014), a propriedade comunal dos meios de produção e a administração e trabalho coletivo, do modo de produção associado descrito por Marx, é abordada em conjunto a visão da importância das condições naturais (inalienáveis e indispensáveis) para a existência humana, que acarreta limitações aos direitos de propriedade comunais, objetivando a sustentabilidade destas condições no longo prazo.

A essencialidade da cooperação está implícita na forma de organização do planejamento e produção associada, bem como para a produção pró-ecológica e para o autodesenvolvimento dos indivíduos e da diversidade humana. Esta diversidade acarreta multiplicidade de valores, inclusive ecológicos, mas estes devem compor um senso compartilhado de unidade e responsabilidade em relação as condições naturais e de vida humana. Assim, a ética ecológica é uma ética comunal condizente com a proposta por Marx como essencial à produção associativa, e reforçada pela difusão do conhecimento científico e pelo reconhecimento da essencialidade das condições naturais para a vida (BURKETT, 2014).

${ }^{29}$ Hudis (2012) ressalta que essa evolução não pode ser imposta, deve emergir dos próprios indivíduos livremente associados.

30 Marx não inclui nestas o consumo supérfluo que se relaciona à produção massiva do capitalismo, inviabilizando o argumento que o modo de produção associado seria tão prejudicial ao meio ambiente quanto o capitalismo, ou até mais, pois permite uma maior expansão da acumulação (BURKETT, 2014). 
Com base em todas essas evidências sobre a compatibilidade da produção associativa com uma produção ecologicamente sustentável, Burkett (2014) aponta que a construção desta nova forma de organização social, depende de uma nova união entre os produtores e as condições de produção (propriedade comunal dos meios de produção), da administração e trabalho coletivo e cooperativo da comunidade, e da difusão do conhecimento científico, consequência dessa desalienação das condições de produção.

É importante destacar que o modo de produção associado embora compatível com uma produção ecologicamente sustentável não necessariamente o é, não há determinismo. Mas a compatibilidade existente entre estes (e inexistente no capitalismo), possibilita a construção deste modo de produção incorporando a preocupação ecológica, uma vez que sem esta a destruição do meio ambiente resulta inevitavelmente no colapso climático.

Além do foco ecológico, outro autor que aborda um modelo alternativo ao capitalismo é Rigi $(2011,2013)$ ao destacar o papel do desenvolvimento tecnológico para a superação deste sistema, possibilitando a produção colaborativa baseada na produção de recursos comuns e caracterizada por: i) ausência de planejamento central e de uma divisão do trabalho administrada; ii) produção coletiva, distribuída em comunidades baseada em redes; iii) participação voluntária e descentralizada da produção; iv) liberdade para os indivíduos escolherem em qual tarefa desejam trabalhar, bem como o período, local e ritmo de trabalho; v) com acesso a um computador e internet, e as habilidades necessárias, qualquer indivíduo pode contribuir para o projeto; vi) só existe um controle, quando há diferentes trajetórias possíveis de desenvolvimento; vii) os recursos comuns digitais são disponibilizados livremente na rede; viii) uso não é condicionado a contribuição no processo produtivo; ix) colaboradores não recebem remuneração por suas contribuições.

O principal exemplo do autor é a forma de desenvolvimento dos softwares livres, como é o caso do sistema operacional Gnu/Linux, que é desenvolvido e aprimorado através de uma cooperação em escala global. Além da descrição da forma organizacional da produção deste sistema, o autor aborda o desenvolvimento do primeiro direito de propriedade globalmente inclusivo, o GPL (General Public License), destacando o papel revolucionário desta criação em meio a transformação do conhecimento em fonte de renda no capitalismo informacional, ao estabelecer o conhecimento como uma propriedade coletiva da humanidade. Contudo, essa forma de produção pode ser implementada no processo de produção de bens materiais, devido ao aprimoramento e disseminação das impressoras 3D.

Rigi (2013) aponta que a descrição de Marx sobre a fase avançada do comunismo antecipou a produção colaborativa de três modos: i) ausência da lógica da equivalência; ii) negação da alienação transcendendo a divisão do trabalho nos moldes capitalistas; iii) abolição da organização do trabalho centralizada e hierarquizada da produção capitalista e do Estado. É nosso entendimento que, com base na descrição de Marx do modo de produção associado, pode-se destacar outras características em comum com a produção colaborativa, a saber: i) liberdade do indivíduo; ii) a difusão do conhecimento entre os membros da comunidade; e iii) a inexistência de remuneração monetária. 
Rigi (2011 e 2013) aponta que o desenvolvimento tecnológico ampliou as contradições inerentes à natureza do modo de produção capitalista ao expor a natureza desterritorializada do conhecimento e da tecnologia da informação em relação a característica territorial da propriedade e da divisão do trabalho no capitalismo. Em resposta a essas contradições surgiu a produção colaborativa, que contraria radicalmente a lógica do capital. Trata-se de um modo de produção ainda emergente, que demanda uma revolução social e política para tornar os recursos estratégicos e a infraestrutura, recursos comuns partilhados pela humanidade. Sem esta, a produção colaborativa poderá se desenvolver dentro dos marcos capitalistas, sendo utilizada para obtenção de lucro, como já ocorre em certo grau.

Ressalta-se que nenhuma destas alternativas se constroem por si só, todas necessitam de uma revolução social para a sua viabilidade. Isso é apontado tanto por Rigi (2013) quanto por Burkett (2014), e corrobora a tese de Marx, que não apresentava uma visão determinística do progresso ${ }^{31}$, no sentido de que o desenvolvimento do capitalismo levaria fatalmente ao socialismo. Muito pelo contrário, a história não era vista como algo que conduz os homens e com um final pré-determinado. Para Marx (2012a) são os homens agindo em vias de alcançar seus objetivos que fazem a história.

Portanto, a ausência de um projeto político nesta direção é preocupante em vista da sua essencialidade e urgência, imposta pelo aprofundamento das contradições do processo de acumulação capitalista. Contudo, a mudança ideológica pode estar começando a se difundir.

\subsection{A Economia de Francisco e Clara}

Além dessas propostas no meio acadêmico, em maio de 2019 o líder mundial da Igreja Católica, Papa Francisco, convocou os jovens, economistas e empresários, para um encontro internacional pela economia de Francisco e Clara, que seria realizada na cidade de Assis. Objetivando estudar e colocar em prática uma economia diferente, humanizada, inclusiva e sustentável. Esta nova economia deve partir da perspectiva da interligação entre meio ambiente, justiça social, dignidade dos trabalhadores e direito das gerações futuras, na busca de soluções para os problemas estruturais da economia mundial. Tal modelo econômico seria "fruto da comunhão, baseado na fraternidade e equidade" (VATICANO, 2019).

Apontando a aproximação dessa nova economia aos mandamentos divinos e ao bem comum, bem como sua centralidade no ser humano e no meio ambiente, o pontífice convidou os economistas e empresários a "combater a cultura do descarte" e "propor novos estilos de vida" que não produza vítimas sociais. A carta convite do Papa destaca ainda a abertura a todos os que desejam pensar e praticar uma economia mais atenta aos indivíduos excluídos, "um novo humanismo", independentemente de crença ou religião.

\footnotetext{
${ }^{31}$ Para mais detalhes sobre o tema ver Chattopadhyay (2006).
} 
O encontro estava marcado para março de 2020, com mais de 2000 inscritos de 115 países e com a confirmação de participações de Jeffrey Sachs, Joseph Stiglitz, Amartya Sen, Vandana Shiva, Muhammad Yunus e Kate Raworth, mas em virtude da pandemia do coronavírus foi adiado para novembro (LIMA 2020).

Em nosso entendimento a Economia de Francisco e Clara consiste em uma iniciativa que demanda a elaboração de projetos e de ações concretas, em direção a uma nova forma de organização socioeconômica, uma vez que a centralidade no ser humano, na dignidade, equidade e na preservação de meio ambiente não são compatíveis com o sistema capitalista. Essa proposta se aproxima, inclusive, da concepção de Marx sobre comunismo, abordado como o desenvolvimento humano de forma holística, em sentido cultural e ecológico, e não na mera transformação das relações de produção. Burkett (2014) ressalta que é em razão dessa visão mais ampla que Marx enfatiza a necessidade da cooperação, do planejamento democrático, da redução do tempo de trabalho e do desenvolvimento de novas formas de produção, menos prejudiciais ao meio ambiente. $\mathrm{O}$ que também está alinhado à proposta do pontífice para uma nova economia.

O contexto da atual pandemia estimulou algumas iniciativas em direção a uma nova forma de pensar a sociedade focada no ser humano e não no lucro, como a defendida pela Articulação Brasileira pela Economia de Francisco e Clara (ABEFC), que convocou todos os indivíduos, a agir visando o atendimento das necessidades básicas dos mais vulneráveis, destacando a importância da taxação das grandes fortunas e lucros, redistribuição de renda com instituição de uma renda básica cidadã, manutenção do emprego e renda dos trabalhadores, prioridade de compras nos micro e pequenos empreendimentos, supressão ou redução de alugueis durante o período de crise, doações e atendimento aos mais pobres etc. (ABEFC, 2020).

Essa crise pode ser o raro momento que "o impossível parece possível”, pode ser o início de uma revolução cultural que coloque o desenvolvimento humano e a preservação ambiental no centro das discussões, e que surjam propostas e oportunidades para uma verdadeira revolução na organização socioeconômica. Entretanto, como já apontava Marx, a mudança deve ser construída pelos próprios indivíduos, são os oprimidos que devem lutar por sua emancipação, através de sua união contra os interesses estabelecidos. Ou, novamente, as condições objetivas essenciais para a mudança deixarão de existir. Um novo momento oportuno pode ocorrer tarde demais para evitar as terríveis perdas humanas e naturais que a crise climática engendrará. Cabe destacar que embora tenha ampliado as discussões sociais sobre renda universal, essa não resolve a crise ambiental e outras contradições intrínsecas ao sistema. E falta um programa político de superação do capitalismo e discussões sociais avançada sobre o tema, fatores que impossibilitam que a crise se torne um ponto de ruptura do sistema capitalista e momento de transição para novo modo de organização socioeconômica. 


\section{Conclusão}

Entre as consequências que essa pandemia, COVID-19, trará a economia mundial, uma das mais evidentes será o maior papel dos governos na condução da economia, especialmente nos países de capitalismo avançado. Contudo, mesmo a maior participação do Estado na economia, não consegue eliminar diversas contradições inerentes ao sistema capitalista e suas consequências negativas aos indivíduos, ao meio ambiente e a própria espécie humana.

Será que podemos esperar pela difusão da consciência social e ambiental enquanto nos mantemos todos keynesianos? Ainda será possível reverter as piores consequências da crise climática, quando finalmente a mudança cultural atingir as massas, e todos nos tornarmos ecologistas, ou socialistas, ou humanistas?

No contexto atual de uma pandemia que afeta todos os países, e aflora as contradições do sistema capitalista, a discussão sobre a superação do modo de produção capitalista se torna mais urgente e evidente, impossível de ser adiada. A alteração de formas de condução da economia capitalista (liberalismo clássico, capitalismo regulado, neoliberalismo etc.) não foram suficientes para resolver os problemas das crises cíclicas da economia e o problema social. Jamais poderiam fazê-lo uma vez são intrínsecos e necessários ao capitalismo.

É preocupante a falta de um projeto político de superação da atual forma de organização das relações sociais de produção, mesmo diante de seus efeitos nocivos sobre o meio ambiente e suas consequências, que ameaçam as condições de sobrevivência dos seres humanos, sem mencionar todas as formas de vida na terra.

A discussão de alternativas ainda se centra em certas correntes do meio acadêmico, e mais recentemente tem se fortalecido uma vertente na Igreja Católica, liderada pelo Papa Francisco, que busca uma mudança da visão de como a economia deve servir ao seres humanos e não o oposto, e como vida humana e meio ambiente são indissociáveis, e dever ser protegidos e preservados pelo sistema econômico. Abordagem semelhante a concepção do modo de produção associado de Marx. Discussões nestas novas direções precisam evoluir para propostas efetivas e ações concretas. É preciso uma revolução ideológica e cultural de grande amplitude sobre como a sociedade deve se reinventar após a pandemia.

É nosso entendimento que essa transformação não se opera de forma rápida, ao contrário, mesmo desencadeada por uma pandemia que levou muitos países a crises sanitárias e econômicas, se processa lentamente, e nenhuma conquista no sentido de melhoria das condições de vida e trabalho dos indivíduos, nem as relativas ao meio ambiente, são irreversíveis. Essas demandam uma forte luta de classes para serem obtidas e mantidas, se consolidando somente quanto a mudança ocorrer de forma generalizada entre os países.

Além disso, os países não estão igualmente dotados das bases econômicas do novo, mas enquanto os países de capitalismo avançado em condições para realizar a mudança do sistema socioeconômico não o fazem, os demais países, como o Brasil, devem, além de buscar construir essas bases materiais para a mudança, concentrar-se na construção de 
propostas políticas, na alteração ideológica e no incentivo de iniciativas emancipatórias, humanistas e ecologicamente sustentáveis, inclusive como as cooperativas e a economia solidária.

O primeiro passo, imprescindível, em tal direção é a superação da teoria econômica mainstream, mais do que ultrapassada esta teoria não consegue explicar a realidade, as crises capitalistas e, consequentemente, não consegue apontar medidas para a retomada do crescimento, mas reforça a ideologia do individualismo, que precisa ser superada para que a evolução social em direção ao verdadeiro humanismo seja possível. Neste sentido o resgate da teoria econômica de Marx e sua concepção do modo de produção associado é indispensável, ao embasar a construção coletiva de uma organização socioeconômica que possibilite a superação da pobreza, desigualdade, fome, desemprego, destruição do meio ambiente entre outros problemas inerentes ao sistema capitalista.

\section{Agradecimentos}

O presente trabalho foi realizado com apoio da Coordenação de Aperfeiçoamento de Pessoal de Nível Superior - Brasil (CAPES) - Código de Financiamento 001.

\section{Referências}

ABEFC. Um chamado à união entre as religiões por um mundo melhor. A Economia de Francisco, 18.04.2020. Disponível em: https://ecofranbr.org/um-chamado-a-uniao-entreas-religioes-por-um-mundo-melhor/. Acesso em: 22 abr. 2020.

ANDRADE, D. P. Neoliberalismo: Crise econômica, crise de representatividade democrática e reforço de governamentalidade. Novos estudos CEBRAP, v. 38, n. 1, p. 109-135, 2019.

AUTO, D. H. Why are there still so many Jobs? The history and future of workplace automation. Journal of Economic Perspectives, v. 29, n. 3, p. 3-30, 2015.

BELLO, W. The food wars. London-New York: Verso, 2009.

BILL Clinton's Trade Policies Destroyed Haitian Rice Farming, Now Haiti Faces PostHurricane Famine. Democracy Now! 11.10.2016. Disponível em: https://www.democracynow.org/2016/10/11/bill_clinton_s_trade_policies_destroyed. Acesso em: 16 jul. 2020.

BURKETT, P. Marx and Nature: A red and green perspective. Chicago: Haymarket Books, 2014. Não Paginado. 
CHATTOPADHYAY, P. Passage to socialism: the dialectic of progress in Marx. Historical Materialism, v. 14, n. 3, p. 45-84, 2006.

CHATTOPADHYAY, P. On Market Socialism. In: Socialism and Commodity

Production: Essay in Marx Revival. Boston: Brill, 2018. (Historical materialism book series; 165). p. 199-231.

CORREIA, S.; LUCK, S.; VERNER, E. Pandemics Depress the Economy, Public Health Interventions Do Not: Evidence from the 1918 Flu. 2020. Disponível em: https://ssrn.com/abstract=3561560. Acesso em: 22 abr. 2020.

DEGRYSE, C. Digitalisation of the economy and its impact on labour markets. European Trade Union Institute - ETUI. Working Paper 2016.02, 2016.

DUGGER, W. M. Radical Institutionalism: Basic Concepts. Review of Radical Political Economics, v. 20, n. 1, p. 1-20, 1988.

FINE, B. Economics Imperialism and the New Development Economics as Kuhnian Paradigm Shift. World Development, v. 30, n. 12, p. 2057-2070, 2002.

. The Undead World of Mainstream Economics. London: SOAS Department of Economics - University of London, 2017. (Working Paper, 206).

FREY, C. B.; OSBORNE, M. A. The future of employment: How susceptible are jobs to computerisation? Technological Forecasting \& Social Change, v. 114, p. 254-280, 2017.

FORD, M. Rise of the robots: technology and the threat of a jobless future. New York: Basic Books, 2015.

FUCHS, C. Digital Labor and Karl Marx. New York: Routledge, 2014.

HAUBRICH, D. B.; FROEHLICH, C. Benefícios e desafios do home office em empresas de tecnologia da informação. Revista Gestão \& Conexões, v. 9, n. 1, p. 167-184, jan./abr. 2020.

HUDIS, P. Marx’s Late Writings on Postcapitalist Society. In: Marx's Concept of the Alternative to Capitalism. Leiden-London: Brill, 2012. (Historical materialism book series; 36). p. 183-206.

HUNT, R. N. The Political Ideas of Marx and Engels. Vol. I: Marxism and Totalitarian Democracy, 1818-1850. Pittsburgh: University of Pittsburgh Press, 1974.

IBGE. Síntese de indicadores sociais: uma análise das condições de vida da população brasileira 2019. Estudos e Pesquisas, Informação Demográfica e Socioeconômica, n. 40. Rio de Janeiro: IBGE, 2019.

JOSSA, B. Cooperative Firms as a New Mode of Production. Review of Political Economy, v. 24, n. 3, p. 399-416, 2012. 
KLEIN, N. This changes everything: capitalism vs. the climate. New York: Simon \& Schuster, 2014. Não Paginado.

LAYRARGUES, P. P. Pandemias, colapso climático, antiecologismo: educação ambiental entre as emergências de um ecocídio apocalíptico. Revista Brasileira de Educação Ambiental, v. 15, n. 4, p. 01-30, 2020.

LIMA, R. A economia de Francisco: construir novos caminhos. Vatican News, Cidade do Vaticano, 22.02.2020. Disponível em:

https://www.vaticannews.va/pt/vaticano/news/2020-02/editorial-economia-franciscoconstruir-novos-caminhos-assis.html. Acesso em: 16 abr. 2020.

MALDONADO FILHO, E. Marx e o Capitalismo Contemporâneo. In: PAULA, J. A. (Org.). Adeus ao desenvolvimento: a opção do governo Lula. Belo Horizonte: Autêntica, 2005.

A crise do capitalismo norte-americano. 2013.

MARX, K. O Capital: crítica da economia política. 34. ed. Rio de Janeiro: Civilização Brasileira, 2016 [1867]. Livro Primeiro, Volume I.

O Capital: crítica da economia política. 29. ed. Rio de Janeiro: Civilização Brasileira, 2015 [1867]. Livro Primeiro, Volume II.

O Capital: crítica da economia política. 15. ed. Rio de Janeiro: Civilização Brasileira, 2016a [1885]. Livro Segundo, Volume III.

. O Capital: crítica da economia política. Rio de Janeiro: Civilização Brasileira, 2008 [1894]. Livro Terceiro, Volume IV.

As lutas de classes na França. 1. ed. São Paulo: Boitempo, 2012 [1850]. (Coleção Marx-Engels).

. Crítica ao Programa de Gotha. São Paulo: Boitempo, 2012a [1875]. (Coleção Marx-Engels).

O 18 de brumário de Luís Bonaparte. São Paulo: Boitempo, 2011 [1852]. (Coleção Marx-Engels).

Instructions for the delegates of the provisional General Council: the different questions. In: Marx, K. e Engels, F. Selected Works. Moscow: Progress Publishers, v. 3, 1970 [1866].

MENDES, D. C.; HASTENREITER FILHO, H. N.; TELLECHEA, J. A realidade do trabalho home office na atipicidade pandêmica. Revista Valore, v. 5, p. 160-191, 2020.

OSTRY, J. D.; LOUNGANI, P.; FURCERI, D. Neoliberalism: oversold? Finance \& Development, v. 53, n. 2, p. 38-41, 2016. 
PAPA FRANCISCO. Carta do Papa Francisco para o evento "economy of Francesco".

La Santa Sede. Cidade do Vaticano, 01.01.2019. Disponível em: https://www.vatican.va/content/francesco/pt/letters/2019/documents/papafrancesco_20190501_giovani-imprenditori.html. Acesso em: 16 abr. 2020.

PANDEMIA e meio ambiente: impactos momentâneos ou nova normalidade? UFJF Notícias. 24.04. 2020. Disponível em:

https://www2.ufjf.br/noticias/2020/04/24/pandemia-e-meio-ambiente-impactosmomentaneos-ou-nova-normalidade/. Acesso em: 19 jul. 2020.

PRZEWORKI, A. Social Democracy as a Historical Phenomenon. In:

Capitalism and social democracy. New York: Cambridge University Press, 1989. p. 746.

ROBERTS, M. The crisis of capitalism in the 21st Century. Revista Linhas. v. 21, n. 46, p. 16-49, 2020.

. A people's guide to capitalism. 2020a. Disponível em:

https://thenextrecession.wordpress.com/2020/10/25/a-peoples-guide-to-capitalism/. Acesso: 03 nov. 2020

SCHWAB, K. A Quarta Revolução Industrial. São Paulo: Edipro, 2016.

SOUZA, E. A. L. A constituição federal de 1988 e a vedação a "escolha da Sofia" na covid-19. Brazilian Journal of Health Review, v. 3, n. 4, p. 10600-10610, 2020.

UNCTAD. From global pandemic to prosperity for all: avoiding another lost decade. Trade and Development Report 2020. Geneva: United Nations Publications, 2020.

WENGRAF, L. Extracting profit: imperialism, neoliberalism, and the new scramble for Africa. Chicago, Illinois: Haymarket Books, 2018.

WHO - World Health Organization. WHO Coronavirus Disease (COVID-19)

Dashboard. Last update: 20.05.2021. Disponível em: https://covid19.who.int/. Acesso em: 20 maio 2021.

WOETZEL, J.; PINNER, D.; SAMANDARI, H.; ENGEL, H.; KRISHNAN, M.;

KAMPEL, C.; VASMEL, M. Will mortgages and markets stay afloat in Florida? Case study. McKinsey Global Institute, p. 1-30, 2020. 